\title{
EUGENIAMYIA DISPAR GEN.N. AND SP.N. (DIPTERA, CECIDOMYIIDAE, LASIOPTERIDI) ASSOCIATED WITH EUGENIA UNIFLORA L. (MYRTACEAE) IN BRAZIL
}

\author{
Valéria Cid Maia ${ }^{1}$ \\ Milton de S. Mendonça Júnior 2, 3 \\ Helena P. Romanowski ${ }^{2}$
}

\begin{abstract}
A new genus and species Eugeniamyia dispar (Diptera, Cecidomyiidae, Lasiopteridi) that cause leaf galls on Eugenia uniflora L. (Myrtaceae) in Brazil, is described.

KEY WORDS. Diptera, Cecidomyiidae, Eugeniamyia dispar, Myrtaceae, Eugenia uniflora, taxonomy
\end{abstract}

Leaf galls on Eugenia uniflora L. (Myrtaceae) were collected in southern Brazil. Branches bearing mature galls were cut off the plants and maintained in small pots with wet soil, covered by transparent plastic cilinder about $30 \mathrm{~cm}$ high, to obtain the adults.

The material was prepared following the methods described in GAGNÉ (1989), except for the immersion in acetic carmime for five minutes after the acetic acid. This procedure was adopted to have better observation of the specimens. After the acetic carmime the material returned to acetic acid for another five minutes.

Eugeniamyia belongs to the tribe Oligotrophini based on GAGNÉ (1994) key. The Oligotrophini are represented by 43 genera in the neotropical region, including Eugeniamyia. This genus seems to be close to Promikiola Kieffer \& Herbst, 1911 on the basis of the combination of the following female characters: four palp segments, toothed tarsal claws, ovipositor barely protrusible and cerci separated. It differs from Promikiola by the lowest number of antennal flagellomeres (17 in Promikiola; 14 in Eugeniamyia) and the lenght of $\mathrm{R}_{5}$ (as long as the wing in Promikiola; shorter than the wing in Eugeniamyia). Larvae and males could not be compared because those of Promikiola are still unknown.

\section{Eugeniamyia gen.n.}

Figs 1, 4-10

Diagnosis. antenna with 14-18 cylindrical flagellomeres, necks longer in male than in female (male: neck of flagellomere 5 approximately $1 / 3$ as long as the

1) Museu Nacional. Quinta da Boa Vista, São Cristóvão, 20940-040 Rio de Janeiro, Rio de Janeiro, Brasil.

2) Departamento de Zoologia, Instituto de Biociências, Universidade Federal do Rio Grande do Sul. Avenida Paulo Gama, 90040-060 Porto Alegre, Rio Grande do Sul, Brasil.

3) Fellowship CAPES.

Revta bras. Zool. 13 (4): 1087 - 1090, 1996 
total lenght of flagellomere; female: neck of flagellomere 5 approximately $1 / 7$ as long as the total lenght of flagellomere); circumfila anastomosing. Palpus four-segmented. Tarsal claws toothed, longer than empodium. Ovipositor barely protrusible, cerci separated. Gonocoxite and gonostylus short, parameres separated and welldeveloped, aedeagus short. Larva: spatula developed, apical teeth absent; eight terminal setose papillae (seta of uniform lenght).

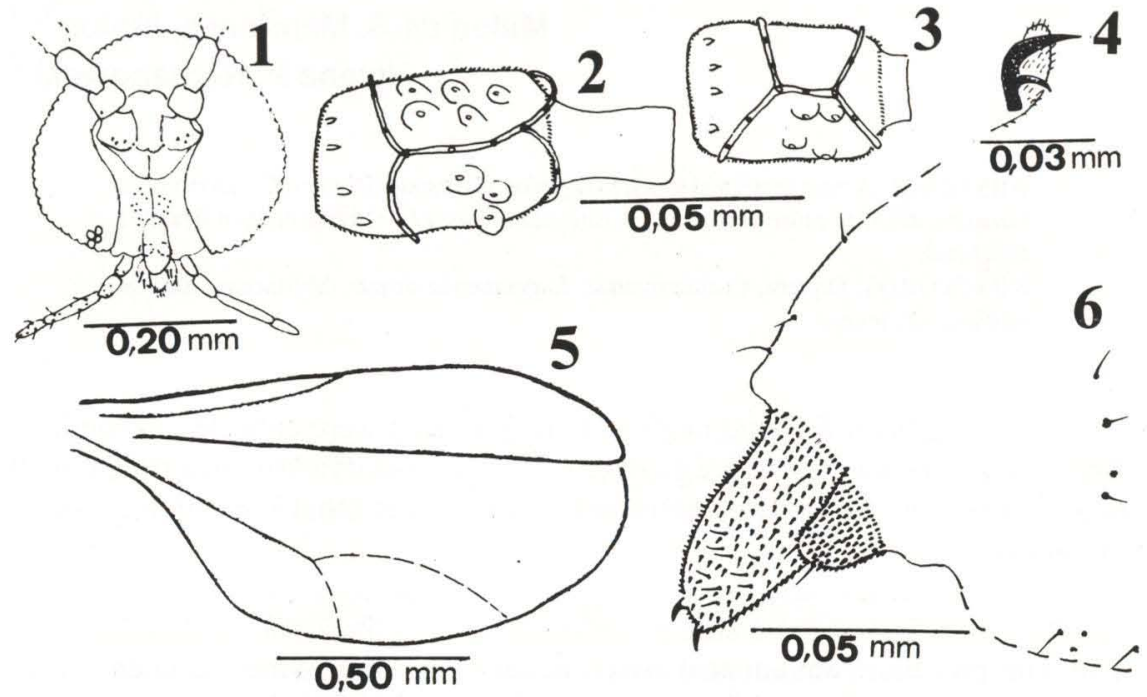

Figs 1-6. Eugeniamyia dispar sp.n.. (1) Male, head (frontal); (2) male, flagellomere 5; (3) female, flagellomere 5; (4) male, wing; (5) male, tarsal claw and empodium; (6) ovipositor (lateral).

Adults. Head (Fig. 1): palpus 4-segmented, segment 1 the shortest, segment 2 the widest, 3 and 4 subequal in lenght, all with setae. Labellae hemispherical, setose. Wing (Fig. 4): C with a break just after insertion of R5; R5 straight, shorter than wing; Sc, Rs, $\mathrm{M}_{3}$ and $\mathrm{CuP}$ absent; $\mathrm{Cu}$ forked. Legs: tibial spurs absent; tarsal claws toothed and bent beyond basal third; empodium shorter than claws (Fig. 5). Abdomen: tergites 1-7 in male and 1-6 in female rectangular, sclerotized, with a caudal row of setae, no lateral setae and covered elsewhere with scales; male tergite 8 shorter than preceeding tergites, sclerotized, with one trichoid sensila; female tergite 6 shorter than preceding tergites, rectangular, with 3-4 caudal rows of setae. Sternites 2-8 in male, 2-7 in female rectangular, with 1-4 caudal rows of setae and a band of setae across midlenght, more numerous laterally, scattered setae elsewhere. Female sternite 8 unsclerotized. Ovipositor (Fig. 6) barely protrusible; female cerci well-developed, separated and setose, each lobe with one pair of setae stronger than the remainding. Male terminalia (Fig. 7): gonocoxite stout; gonostylus triangular and completely setulose; cerci deeply bilobed, hypoproct slightly bilobed, both setose. Parameres longer than hypoproct and cerci. Aedeagus wide, rounded apically. 
Larva (last instar). Integument rough; spatula with apex roundish without teeth (Fig. 9), stalk developed. Terminal segment with eight papillae, four per side, each with seta of uniform lenght (Fig. 10).

\section{Type-species. Eugeniamyia dispar sp.n.}

Etymology. The name Eugeniamyia is a reference to the host-plant Eugenia.

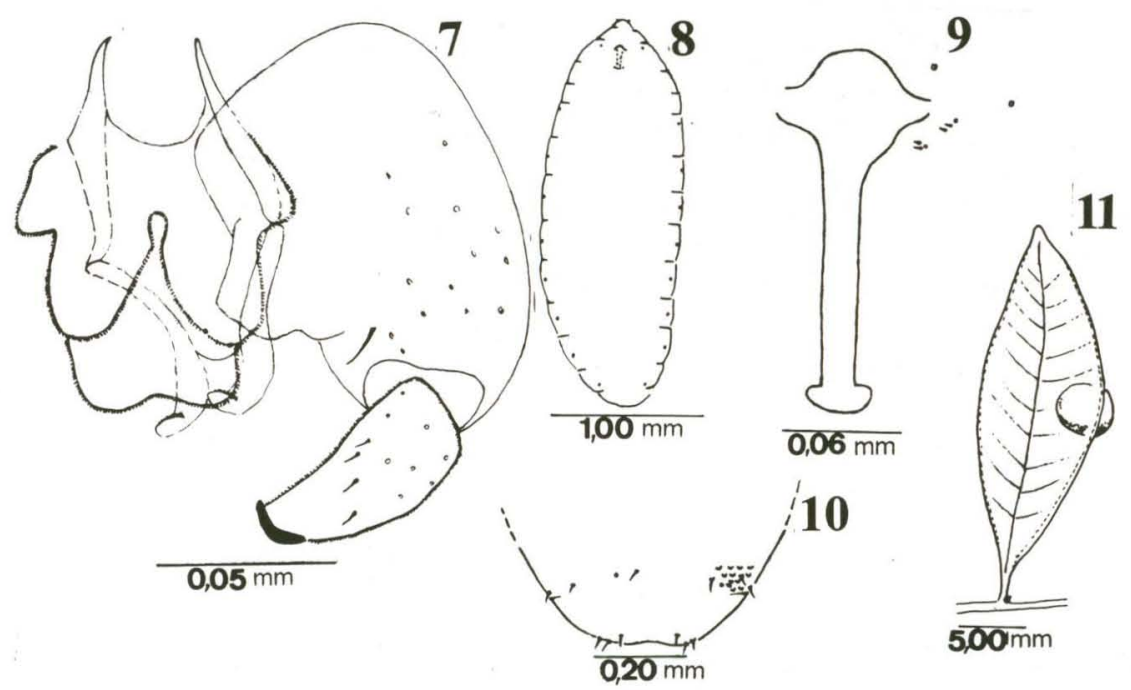

Figs 7-11. Eugeniamyia dispar sp.n.. (7) Male terminalia (dorsal); (8) larva, general aspect (ventral); (9) larva, sternal spatula and lateral papillae (ventral); (10) larva, terminal segment (dorsal); (11) gall, general aspect.

\section{Eugeniamyia dispar sp.n.}

Figs 2-9, 11

Adults. Body lenght: 1.8-2.0mm; wing lenght: $2.5-2.9 \mathrm{~mm}$. Head: eyes with circular facets. Antenna: flagellomeres 1 and 2 fused, circumfila as in figures 2 and 3 ; flagellomere 12 without apical process. Thorax: mesonotum with 4 longitudinal setal rows; anepimeron with a longitudinal setal row; anepisternum bare. Wing: venation as in figure 4 . All legs with tarsal claws toothed longer than empodium (Fig. 5). Ovipositor as in figure 6, female hypoproct setulose, each lobe with 2 apical setae. Male terminalia (Fig. 7): gonocoxite stout and short, about 1.5 times as long as large; gonostylus short (about 2.0 times shorter than gonocoxite and 2.0 times as long as wide); hypoproct longer than cerci; parameres as in figure 7.

Larva. Colour: white. Body lenght: $3.0-3.2 \mathrm{~mm}$. General aspect as in figure 8. Thorax: spatula with lenght of $0.20-0.23 \mathrm{~mm}$, general aspect as in figure 9 ; thoracic and abdominal segments with the basic papillar pattern. Abdomen: segments 1-7 with lateral spiracles; abdominal segment 8 with pre-apical spiracles. The third instar larva leaves its gall and pupate in the soil. 
Material examined. Holotype male: BrASIL, Rio Grande do Sul: Porto Alegre (urban area), 10-X-1995, M. Mendonça Júnior leg.. Paratypes: Same data as holotype: 14 male, 2 female, 3 larvae. Other specimens examined: 18 male, 10-X-1995 and 1 female, I-II-1995. This material was obtained from leaf galls on Eugenia uniflora L. (Myrtaceae) and all specimens are deposited in the Diptera collection of "Museu Nacional/UFRJ".

Etymology. dispar (different) refers to the peculiar aspect of male terminalia.

Galls (Fig. 11). The galls of Eugeniamyia dispar are induced on young leaves and shoots of its host by first instar larvae. The number of galls per leaf varies from one to thirty. The galls are spherical, 3.5 to $4.5 \mathrm{~mm}$ in diameter and white in colour by lack of pigments. The galls are spongy, with a high content of water, and each have only one central chamber, with one larva. So far these galls have only been found in Porto Alegre, Ijuí and "Parque Florestal Estadual de Nonoai", all in Rio Grande do Sul, and in Florianópolis, Santa Catarina, Brazil.

ACKNOWLEDGMENTS. To Dr. Márcia Souto Couri (Museu Nacional, Universidade Federal do Rio de Janeiro) for reviewing the manuscript.

\section{REFERENCES}

GAGNÉ, R.J. 1989. The Plant-Feeding Gall Midges of North America. Ithaca, Comstock Cornell University Press, 356p. 1994. The gall midges of Neotropical region. Ithaca, Comstock Cornell University Press, 352p.

Recebido em 19.VII.1996; aceito em 27. XII.1996. 